\title{
DETERMINANTES DA POBREZA NO MEIO RURAL BRASILEIRO ${ }^{1}$
}

Patricia de Melo Abrita Bastos ${ }^{2}$; Leonardo Bornacki de Mattos ${ }^{3}$; Gilnei Costa Santos ${ }^{4}$

\begin{abstract}
Resumo
Nesta pesquisa, buscou-se entender os determinantes da pobreza no meio rural brasileiro ao longo do período de 2001 a 2012. A escolha desse corte justifica-se devido às profundas mudanças que têm alterado a dinâmica da renda no meio rural, como o avanço das ocupações não agrícolas, aumento do número de beneficiários de transferências de renda e pelo aumento dos aposentados pelo regime especial de aposentadoria rural. Utilizando dados da PNAD, investigou-se os fatores socioeconômicos e aqueles relativos à produtividade, à infraestrutura e ao tipo de ocupação, a fim de lançar luz sobre as causas associadas ao estado de pobreza no meio rural. Em suma, foi possível constatar que as três principais mudanças pelas quais o meio rural está passando estão contribuindo para a redução da pobreza e desigualdade de renda no meio rural.
\end{abstract}

Palavras-chave: Desigualdades; Bolsa-Família; Aposentadoria.

\footnotetext{
${ }^{1} \mathrm{O}$ autor agradece o apoio financeiro recebido da FAPEMIG (edital Demanda Universal 2015, APQ02933-15). Bolsista de Produtividade em Pesquisa do CNPq.

${ }^{2}$ Doutora em Economia Aplicada pela Universidade Federal de Viçosa. Professora adjunta na Universidade Federal Fluminense - UFF. E-mail: patriciaabrita@gmail.com

${ }^{3}$ Doutor em economia aplicada pela Universidade Federal de Viçosa. Professor Associado no Departamento de Economia Rural da Universidade Federal de Viçosa - DER/UFV. E-mail: lbmattos@ufv.br

${ }^{4}$ Mestre em Economia pela Universidade Federal de Viçosa. E-mail: gilnei@ icloud.com
} 


\title{
Determinants of poverty in the Brazilian rural areas
}

\begin{abstract}
In this paper, we sought to understand the determinants of poverty in the Brazilian countryside in the years from 2001 to 2012. In this period there were intensive changes that have altered the dynamics of income in rural areas, such as the Non-agricultural occupations, an increase in the number of beneficiaries of income transfers, and an increase in retirees by the special rural retirement scheme. Using PNAD data, we sought to investigate socioeconomic factors and those related to productivity, infrastructure and occupation type, in order to shed light on the causes associated with the state of poverty in rural areas. We concluded that the three main changes observed in the rural areas contribute to the reduction of poverty and income inequality in these areas.
\end{abstract}

Keywords: Inequalities; Bolsa-família; Retirement.

JEL: D60, J78, I32, I38, O18

\section{Considerações iniciais}

O Brasil é considerado um país com muitas pessoas ainda em estado de pobreza ${ }^{5}$, miséria e indigência ${ }^{6}$, fome e desnutrição ${ }^{7}$, mesmo diante de expressivas riquezas naturais e elevado Produto Interno Bruto (PIB) ${ }^{8}$. Desse modo, reduzir a pobreza tem sido o grande desafio nacional. Após o controle da inflação, que foi um dos principais problemas das décadas de 1970, 1980 e início de 1990, as atenções se voltaram para a pobreza. Esse

\footnotetext{
${ }^{5}$ A pobreza é uma situação social e econômica caracterizada por carência na satisfação das necessidades básicas. Considerando a abordagem monetária, é aquele indivíduo que está abaixo da linha de pobreza (mínimo de renda). De acordo Campello et al. (2014), não existe uma linha oficial de pobreza no Brasil. Entretanto, o Ministério do Desenvolvimento Social e Combate à Fome (MDS), estabeleceu em 2011, com base no padrão do Banco Mundial (BM), o ponto de corte de R \$ 70,00 per capita para definir famílias em situação de extrema pobreza e o dobro desse valor $(\mathrm{R} \$ 140,00)$ para definir a pobreza. Outros autores, como Rocha (2006), acreditam que a linha de pobreza não deve ser única devido às diferenças existentes na pobreza entre zonas rurais e urbanas, regiões metropolitanas e não metropolitanas. A linha de pobreza, expressa em valor monetário, geralmente é estabelecida por órgãos nacionais e internacionais. Uma discussão pormenorizada sobre linhas de pobreza pode ser encontrada nos trabalhos de Tronco e Ramos (2017) e Rocha (2006).

${ }^{6}$ Designação da circunstância das pessoas que vivem em condições de extrema pobreza, privadas de bens fundamentais para a vida (alimento, casa, roupa, entre outras coisas). Considerando a abordagem monetária, é aquele que está abaixo da metade do valor da linha de pobreza considerada.

7 Têm fome aqueles cuja alimentação diária não aporta a energia requerida para funcionamento e manutenção do organismo para atividades ordinárias do ser humano. Sofrem de desnutrição aqueles que manifestam sinais e sintomas provenientes da insuficiência quantitativa e qualitativa da dieta. Dados do Fundo das Nações Unidas para a Alimentação e a Agricultura (FAO, 2014) considera que tem fome aquele com consumo diário de nutrientes abaixo de 2,2 mil calorias.

${ }^{8}$ Segundo a Organização para a Cooperação e Desenvolvimento Econômico (OCDE), a renda per capita do Brasil foi cerca de 11.800 dólares em 2012 e considerada a sétima economia mundial. Entretanto, no ranking do Índice de Desenvolvimento Humano (IDH), o Brasil ocupa a $85^{\circ}$ posição.
} 
fenômeno está em pauta nas agendas do Governo, nas discussões acadêmicas, em razão da sua gravidade e, por conseguinte, da urgência em mitigar esse problema9 ${ }^{9}$. De acordo com a base de dados do Banco Mundial (2018), alguns países já erradicaram a extrema pobreza, como por exemplo, EUA, Canadá, e países da Europa Ocidental. Por outro lado, ainda são muitos as pessoas em situação de extrema pobreza na África, Ásia e América Latina. Congo, por exemplo, em 2012 ainda possuía mais de 70\% da população neste estado de privação. O Brasil, conseguiu avançar neste quadro, passando de $20,8 \%$, em 2002, para 4,9\% em 2012. Porém ainda está em uma situação pior do que o México e Argentina, que possuíam em 2012,3\% de sua população nesta condição.

De acordo com o IFAD $(2014)^{10}$, o grande número de pessoas abaixo da linha de pobreza no meio rural brasileiro é preocupante devido ao fato de o Brasil ser considerado importante potência agrícola e industrial e também de ser a economia mais forte na América Latina. Os níveis de pobreza e de indicadores de desenvolvimento humano em áreas rurais brasileiras são comparáveis com os países mais pobres da América Latina. Países como Venezuela e México possuem quase a metade da população rural em situação de extrema pobreza, e outros como Brasil e Colômbia concentram parcela significativa dos seus habitantes do meio rural em condições de pobreza, $75 \%$ classificados como pobres e $25 \%$ destes em extrema pobreza.

Segundo relatório da ONU-HABITAT (2012), a situação da pobreza urbana no Brasil é pior em relação aos demais da América Latina. Cerca de $20 \%$ da população vivem em situação de pobreza ${ }^{11}$ no meio urbano brasileiro, percentual maior do que no Uruguai, na Argentina, no Chile e no Peru. Chile, Argentina e Uruguai possuem menos de $12 \%$ da população urbana na pobreza.

Segundo Sawaya et al. (2003), a pobreza rural tem características específicas, distintas da urbana ${ }^{12}$. Por exemplo, a carência de acesso a estradas para escoamento da produção agrícola, a falta de crédito rural, as secas que provocam fome sazonal, a falta de acesso à água, a pouca cobertura dos serviços de saúde etc. são fatores determinantes para a condição de vida e pobreza no meio rural. No que concerne à pobreza no meio

\footnotetext{
${ }^{9}$ Dados do Fundo das Nações Unidas para a Alimentação e a Agricultura (FAO, 2014) indicaram que o Brasil saiu do Mapa Mundial da Fome em 2014. De 2002 a 2013, caiu para 82\% a população de brasileiros considerados em situação de subalimentação.

${ }^{10} \mathrm{O}$ estudo considera as linhas oficiais de pobreza e extrema pobreza declaradas pelo Governo Federal em 2011. Renda domiciliar mensal per capita de até $R \$ 140,00$ situação de pobreza e renda e até $R \$ 70,00$, situação pobreza.

${ }^{11}$ A linha de pobreza adotada neste relatório, aplica o método da CEPAL, baseado nas necessidades básicas, isto é, cálculo do rendimento mínimo necessário para que os membros de uma família possam satisfazer suas necessidades essenciais. Para mais detalhes, vide página 42, do relatório ONU-HABITAT (2012).

${ }^{12}$ Nos censos demográficos, tem-se uma redefinição das áreas rurais e urbanas, em que se observa o estreitamento das áreas rurais, à medida que novas cidades surgem, em alguns casos devido a interesses, como o aumento da arrecadação de impostos, e não por uma mudança estrutural da região. Segundo metodologia do IBGE, quando se trata de cidades, considera-se área urbana. Para uma metodologia alternativa, vide Veiga (2001).
} 
urbano, os principais determinantes são baixa escolaridade materna; a gravidez na adolescência; o desemprego; a violência; o isolamento social; condições de moradia e saneamento inadequadas etc.

O meio rural brasileiro abarca uma grande população que foi excluída do processo de modernização da agricultura ${ }^{13}$. Essas famílias, que antes detinham alguma terra, porém não tinham recursos suficientes e não tiveram acesso ao crédito para participar dessa evolução, ficaram em uma situação precária. Aliado a esse fato, soma-se a escassez de capital humano, educação principalmente, pertinente ao meio rural. As famílias rurais tinham como atividade principal a agricultura, a qual não exigia alta escolaridade. Sem acesso à tecnologia para cultivar a terra (ativo) e sem qualificação (anos de estudo), foram comprometidas, respectivamente, a renda da terra e a entrada no mercado de trabalho. Nesse sentido, pode-se inferir que as famílias rurais entraram em um período amplo de pobreza.

Nos últimos anos, de acordo com Buainain (2012), ocorreram mudanças, entre elas a dissociação entre a economia rural e a agrícola, na qual as atividades desenvolvidas no espaço rural já não são exclusivamente agrícolas. Verificou-se uma redistribuição de atividades, como artesanato, turismo rural etc. Segundo Hespanhol (2014), um conjunto de políticas públicas em diferentes âmbitos, mas principalmente no nível federal, contribuiu para reduzir a pobreza rural no país nas últimas décadas, notadamente a partir dos anos 1990. Dentre elas, destacam-se particularmente o PRONAF (Programa Nacional de Fortalecimento da Agricultura Familiar), o PNRA (Plano Nacional de Reforma Agrária), os Programas Territórios Rurais e Territórios da Cidadania, a universalização da aposentadoria rural e os dois programas de compra institucional da agricultura familiar: o Programa de Aquisição de Alimentos (PAA), instituído no ano de 2003, no âmbito do Fome Zero, e o Programa Nacional de Alimentação Escolar (PNAE), que a partir de 2009, passou a exigir que no mínimo 30\% das aquisições de alimentos realizadas pelas prefeituras com verbas do Fundo Nacional de Desenvolvimento da Educação (FNDE) sejam feitas diretamente de organizações de agricultores familiares, por intermédio de chamadas públicas.

Embora mais enfático nos dias atuais, o debate sobre pobreza e as tentativas de mensuração são antigos na literatura socioeconômica ${ }^{14}$. Desde então, foram traçados vários conceitos e perfis, cujas análises começaram no campo empírico. Logo após, surgiram algumas teorias para explicar o fenômeno. De acordo com Silva (2015), até a década de 1960, predominou o conceito de necessidades insatisfeitas ${ }^{15}$. Na década de

\footnotetext{
${ }^{13}$ De acordo com a PNAD de 2009, entre um total de 30,7 milhões de pessoas residentes no meio rural, 8,4 e 8,1 milhões delas eram classificadas como pobres e extremamente pobres, a partir da renda per capita mensal de até $1 / 2$ salário mínimo e 1/4 do salário mínimo, respectivamente.

14 Vide Townsend (1954).

${ }^{15}$ Se estabelece um conjunto de indicadores ligados à renda familiar, assistência escolar, acesso a serviços sociais e condições de habitação. Para realizar o cálculo, define-se um padrão mínimo e se considera como pobre a família que se encontra abaixo do padrão em pelo menos uma das necessidades.
} 
1970, o conceito absoluto de pobreza cede lugar para o relativo. Passou-se, então, a considerar como pobre aquele indivíduo ou família cujo consumo estava abaixo do padrão médio de determinada sociedade, ou que não possuía o mínimo necessário para viver de acordo com o status social verificado na sociedade em que estão inseridos. Na década de 1980, a pobreza começa a ter ligações com o conceito de exclusão. Para Paugman (1999), trata-se de mais um paradigma social do que um verdadeiro conceito. Na década de 1980, também se verificou a preocupação em analisar a pobreza de uma forma multidimensional, observando quais as características mais adequadas que, em conjunto, determinam o estado de privação. Nessa perspectiva, a pobreza é definida como a ausência de determinadas capacitações básicas que possibilitem atingir níveis minimamente aceitáveis de alguns funcionamentos ${ }^{16}$. Esta discussão em torno das capacitações foi iniciada no final da década de 1970, tendo como mentor o economista Amartya $\operatorname{Sen}^{17}$.

Atualmente, cresce a preocupação com o tempo em que o indivíduo permanece em estado de privação. Segundo Nunes (2004), a introdução da dimensão temporal permite verificar quais grupos sociais são mais vulneráveis à persistência na pobreza, não observados nos estudos que utilizam dados de seção cruzada de natureza estática. Quando o período de estado de privações é curto, as famílias podem amenizar essa situação buscando empréstimos, reduzindo gastos, vendendo alguns objetos de valor etc. Quando a pobreza persiste por um período maior, a situação fica insustentável, e as consequências são muitas, sendo duas das piores: a desnutrição e a fome. Para Hulme e Shepherd (2003), a pobreza crônica, persistindo por um longo tempo na vida de um indivíduo, pode ser passada de geração para geração, importante fator para iniciar um ciclo vicioso.

Espera-se que a dinamização do mercado de trabalho rural revelada nos últimos anos, aliada ao aumento do número de aposentados e o crescimento do número de beneficiados pelos programas sociais, tenha contribuído para alterar o rendimento das pessoas ocupadas no campo e colaborado para a redução da pobreza. Neste âmbito, buscase verificar o impacto dessas mudanças, relatadas por Buainain (2012) e Hespanhol (2014), para a pobreza no meio rural e a evolução do perfil da pobreza. O estudo analisado nesse período, em que essas políticas de combate à pobreza no meio rural foram implementadas, permitirá verificar a eficácia dessas medidas ao longo dos anos. Será possível verificar em que ano tivemos uma maior redução da pobreza e associá-lo às

\footnotetext{
${ }^{16}$ A capacidade é um tipo de liberdade: a liberdade substantiva de realizar combinações alternativas de funcionamentos ou a liberdade para ter estilos de vida diversos. Por exemplo, uma pessoa abastada que faz jejum por sua livre e espontânea vontade pode ter a mesma realização de funcionamento que uma pessoa pobre forçada a passar fome extrema. Porém, a primeira pessoa possui um "conjunto capacitário" diferente do da segunda. A primeira pode escolher comer bem e ser bem nutrida de um modo impossível para a segunda (SEN, 1999).

17 Vide Sen (1976), Sen (1980), Sen (1992), Sen (2000) e Sen (2001).
} 
medidas implementadas em cada ano. Observar se a melhora foi contínua, bem como se os determinantes sofreram alterações expressivas ao longo dos anos.

Embora a persistência da pobreza seja medida em relação ao tempo que o indivíduo permanece em estado de privação, verifica-se que boa parte das pessoas que são classificadas como em estado de pobreza extrema também são classificadas como em estado de pobreza crônica. No meio rural brasileiro, o número de pessoas em estado de pobreza extrema sempre foi preocupante e por isso, busca-se contribuir para essa discussão a partir de um estudo da pobreza por um período mais amplo, de 2001 a 2012.

\section{Metodologia}

\subsection{Mensuração da pobreza e seus determinantes no meio rural brasileiro}

Nesta seção, é apresentado o método de Foster et al. (1984) para mensuração da pobreza e o modelo logit utilizado para caracterização da evolução dos determinantes da pobreza no meio rural, de 2001 a 2012.

O índice de Foster, Greer e Thorbecke (FGT) permite identificar a proporção de pobres (número de pobres), a intensidade da pobreza (distância média à linha de pobreza) e a severidade (ponderação maior para a distância média em relação à linha de pobreza, quadrado do hiato da pobreza em relação à linha de pobreza. Para verificar os determinantes da pobreza, utiliza-se um modelo de probabilidade discreta, o logit. Ambas as análises são realizadas nos anos 2001 a 2012, para o meio rural brasileiro ${ }^{18}$.

A unidade de análise é a família, entre as opções: pessoas (sem restrição), as economicamente ativas, apenas as ocupadas, as famílias ou os domicílios ${ }^{19}$. Nesta pesquisa, optou-se pela linha de pobreza absoluta para abarcar as diferenças pertinentes de cada Estado, como proposto por Rocha (2006), e também porque em países em desenvolvimento, como o Brasil, é importante avaliar a pobreza em termos absolutos, relacionado diretamente com questões de sobrevivência física. A pobreza relativa envolve questões de convívio social e se confunde um pouco com o conceito de desigualdade, por isso é mais pertinente para países desenvolvidos.

\footnotetext{
${ }^{18}$ A descrição da metodologia adotada para a construção da linha de pobreza, assim como do procedimento de atualização anual de valores, segue a metodologia apresentada em Rocha (2006): Pobreza no Brasil. Afinal, de que se trata? Editora FGV, Rio de Janeiro. Atualizações em: $<$ http://www.iets.org.br/dado/pobreza-e-indigencia>.

${ }^{19}$ Família é conjunto de pessoas ligadas por laços de parentesco ou normas de convivência, residentes na mesma unidade domiciliar, ou pessoa que mora só em uma unidade domiciliar. Segundo o IBGE, domicílio refere-se às edificações que contenham paredes e teto de qualquer material destinadas à moradia de pessoas. Os domicílios podem ser divididos em coletivos e particulares.
} 
O índice de Foster et al. (1984) apresenta três etapas para o cálculo dessas medidas. A primeira etapa consiste em fixar o valor monetário das linhas de pobreza $\left(z_{p}\right)$. Na segunda etapa, a partir da linha de pobreza, dividem-se os indivíduos em não pobres e pobres. A partir dos microdados da PNAD, verifica-se a renda familiar per capita de cada pessoa e se ela está abaixo dessa linha. Se sim, ela é considera pobre. E, como terceiro passo, se agrega a distância dos pobres à linha de pobreza, de forma a se dar mais ou menos peso aos indivíduos relativamente mais pobres da população.

Após a identificação, buscou-se verificar as causas associadas à pobreza. Dentro de um contexto microeconômico, a maneira mais simples de se analisarem os determinantes da pobreza consiste na utilização de análise de regressão. Para Geda et al. (2001), essa análise pode ser realizada com o emprego de despesa de consumo por cada adulto equivalente, regredindo contra variáveis explicativas potenciais. No entanto, segundo Okwi (1999), as abordagens que utilizam o consumo, como a Pesquisa de Orçamento Familiar (POF) no Brasil, são comprometidas devido à suposição de que o consumo do pobre e o dos não pobres são determinados pelo mesmo processo. Ademais, essas pesquisas não são realizadas anualmente.

Para Fissuh e Harris (2004), outra possibilidade é o emprego de modelos de escolha discreta, como por exemplo o probit e logit, em que a variável dependente é a situação de privação, pobres e não pobres, com base na linha de pobreza adotada. Esses mesmos autores ressaltaram que muitos estudiosos têm adotado essa abordagem, a exemplo de Fofack (2002), Burkina Faso e Kabubuo-Mariara (2002), para o Quênia; Amuedo-Dorantes (2004), para o Chile; Grootaert (1997), para Costa do Marfim; Geda et al. (2001), para o Quênia; Charlette-Gueard e Mesplé-Somps (2001), para Costa do Marfim; e Goaede Ghazouani (2001), para a Tunísia. Pode-se citar também Andersson et al. (2006), para o $\operatorname{LAOS}^{20}$; Singh et al. (2013), para a Índia; e Shams (2014), para o Paquistão.

De acordo com Datt et al. (1999), o conjunto de variáveis com que se pressupõe determinar a renda e, por conseguinte, a pobreza inclui características do agregado familiar e da comunidade. Uma consideração-chave na seleção dos determinantes potenciais da pobreza é escolher variáveis que sejam declaradamente exógenas. Assim, por exemplo, não se incluiu o valor ou a posse dos bens duráveis no grupo de variáveis explicativas porque o valor de uso atribuído aos bens duráveis é um componente do consumo ligado à renda. Do mesmo modo, as características da casa de habitação não integram o modelo, dado que essas provavelmente sejam determinadas pelos padrões de vida do agregado familiar. Tais características determinam rendas reais ou atribuídas que são, também, componentes do consumo total do agregado familiar. Também se omitem, deliberadamente, do modelo variáveis como a frequência escolar atual das crianças, uma

20 Oficialmente, República Democrática Popular é um país asiático, localizado na Indochina, fazendo fronteira ao Norte com a China. 
vez que essas variáveis provavelmente são mais um resultado do que um determinante dos atuais padrões de vida. O conjunto dos determinantes selecionados agrupa-se, em termos gerais, nas seguintes categorias: características da composição familiar, como a idade e o gênero do chefe do agregado familiar, a presença de filhos pequenos; a Educação; emprego (ramos de atividade); posse da terra e acesso à infraestrutura e aos serviços básicos.

Para verificar os determinantes da pobreza no meio rural ao longo dos anos, foi aplicado um modelo logit, fazendo uso de cortes seccionais disponibilizados pela PNAD, de 2001 a 2012, no arquivo de pessoas. Serão utilizadas, além de variáveis relacionadas à produtividade, como educação e experiência que compõem o capital humano, variáveis relacionadas à segmentação de mercado, discriminação racial e de gênero, composição da família, bem como características estruturais pertinentes ao meio rural, a fim de descrever as causas mais importantes para explicar a pobreza no meio rural:

$$
\begin{aligned}
& \text { Pobre }_{i}=\beta_{0}+\beta_{1} \text { Sexo }_{i}+\beta_{2} \text { Idoso }_{-} \mathrm{h}_{i}+\beta_{3} \text { Idoso }_{-} \mathrm{m}_{i}+\beta_{4} \text { Criança }{ }_{-} 17_{i} \\
& +\beta_{5} \text { Criança }_{-} 10_{i}+\beta_{6} \text { Pluriatividade }_{i}+\beta_{7} \text { Fam }_{-} \text {nagricola }_{i}+\beta_{8} \text { Edu }_{i} \\
& +\beta_{9} \text { Eledu }_{i}+\beta_{10} \text { Empregador }_{i}+\beta_{11} \text { Cont } \text { propria }_{i}+\beta_{12} \text { Amarela }_{i} \\
& +\beta_{13} \text { Brancas }_{i}+\beta_{14} \mathrm{Pm} \text { solteiro }_{i}+\beta_{15} \text { Casal }_{i}+\beta_{16} \text { Sudeste }_{i} \\
& +\beta_{17} \text { Centro }_{i}+\beta_{18} \text { Norte }_{i}+\beta_{19} \text { Sul }_{i}+\beta_{20} \text { Rural }_{-} \text {ext }{ }_{-} \text {urbana }_{i} \\
& +\beta_{21} \text { rural } \text { aglo }_{-} \text {iso }{ }_{-} \operatorname{pov}_{i}+\beta_{22} \text { rural } \_ \text {exc } \text { aglo }_{i}+u_{i}
\end{aligned}
$$

Em que a variável dependente Pobre $_{i}$ é uma variável latente, assumindo valor 1 $\left(Y_{i}=1\right)$ se a renda familiar per capita da pessoa estiver abaixo da linha de pobreza e valor $0\left(Y_{i}=0\right)$ quando ocorre o inverso. A renda familiar é composta pelo somatório de todos os rendimentos, monetários, dos membros que compõem a família ${ }^{21}$. Quanto às variáveis explicativas, representam características socioeconômicas disponibilizadas pela PNAD, explicadas a seguir.

A pobreza está relacionada com fatores de vulnerabilidade, como famílias que possuam membros que não participam da população economicamente ativa, a exemplo de idosos e crianças. Desse modo, utilizaram-se as dummies (idoso_ $h_{i}$ ), (idoso_ $m_{i}$ ), (criança $17_{i}$ ), (criança $10_{i}$ ), em que o valor 1 indica a presença de idoso na família da pessoa analisada. Optou-se por distinguir o idoso por gênero, uma vez que a idade para requerer a aposentadoria no meio rural é distinta para homens e mulheres. No que concerne à presença de criança na família, foi realizada a separação por idade, considerando um grupo com crianças de até 10 anos e outro com crianças até 17 anos. A

${ }^{21}$ Para o IBGE (2015), a Pesquisa de Orçamento Familiar (POF) é uma pesquisa mais detalhada que a PNAD. Muitos itens de seu questionário sobre renda não aparecem na PNAD. A PNAD, por exemplo, mede apenas a renda monetária. Vales-alimentação, vale transporte e outros tickets, apurados pela POF, não fazem parte de seus dados de renda. 
partir da literatura ${ }^{22}$, espera-se que essas variáveis, por se tratar de fatores de vulnerabilidade, interfiram negativamente na pobreza, aumentando a probabilidade de ser pobre.

Ainda no que diz respeito à composição da família, espera-se que o estado civil da pessoa de referência interfira no estado de pobreza. Utilizou-se dummy (Pm_solteiro $\left.{ }_{i}\right)$ e $\left(\right.$ Casal $\left._{i}\right)$, em que o valor 1 indica se a pessoa de referência dessa família é casada ou solteira, respectivamente. Chetty et al. (2014) mostraram que o fator mais forte para prever problemas para melhorar de vida é ser criado por mãe solteira, e o fator que melhor prevê crescimento econômico pessoal é ser criado por pai e mãe.

Considerando a Teoria do Capital Humano ${ }^{23}$, é esperado que trabalhadores com mais escolaridade sejam mais eficientes e recebam maiores remunerações. Desse modo, espera-se que a probabilidade de ser pobre reduza com os acréscimos de anos de estudo. Para captar o efeito da Educação $\left(E d u_{i}\right)$, que se trata de uma proxy de produtividade, utilizou-se a variável anos de estudo, que indica o grau de escolaridade da pessoa analisada.

Outra variável empregada foi o efeito limiar da Educação, utilizando uma dummy, em que o valor 1 indica que a pessoa atingiu o limiar $\left(\right.$ Eled $\left.u_{i}\right)$. Segundo Hoffmann e Simão (2005), tem-se um limite a partir do qual os anos de estudo começam a impactar de forma mais expressiva no rendimento. Segundo Ney e Hoffmann (2003), esse valor deve situar-se em 10 anos de estudo. Para o cálculo do $\operatorname{limiar}^{24}$ do meio rural, foram construídas dummies para cada ano de estudo e estimada, primeiramente, uma regressão de rendimento. O limiar é escolhido quando se tem aumento brusco de retorno para cada ano adicional de estudo, seguido de aumento crescente. Espera-se que, a partir desse limiar, a probabilidade de ser pobre seja menor do que para aqueles que possuam escolaridade inferior ao nível estabelecido.

Segundo Barros et al. (2007), nem todas as diferenças em remuneração resultam dessas diferenças intrínsecas de produtividade entre trabalhadores, reveladas apenas pelo mercado de trabalho. O mercado gera desigualdade quando remunera de forma diferenciada homens e mulheres, brancos, amarelos, pardos e negros com a mesma produtividade. Nesse sentido, foram incluídas dummies de gênero $\left(\operatorname{sexo}_{i}\right)$, cor da pele $\left(\right.$ Amarelo $\left._{i}\right),\left(\right.$ Brancas $\left._{i}\right)$, para captar se no meio rural a probabilidade de ser pobre sofre interferência do gênero, da cor da pele, tendo como base homens e negros.

\footnotetext{
${ }^{22}$ Vide Zhang e Wan (2009).

23 A Teoria do Capital Humano explica que a educação e experiência tornam os trabalhadores mais produtivos. Maior produtividade representa maior eficiência econômica, maior geração de produto por unidade de fator de produção e maior nível de produto, (BECKER,1969), (MINCER,1958) e (SCHULTZ,1961).

${ }^{24} \mathrm{O}$ limiar foi definido para cada ano. Para o ano 2008, o limiar foi definido em 12 anos de escolaridade, enquanto em 2001, 2007 e 2011 foram considerados 11 anos, em 200410 anos e em 2002, 2003, 2005, 2006, 2009 e 2012 nove anos.
} 
Outra razão para explicar as disparidades na remuneração é o fato de que estas resultam de segmentação de mercado de trabalhadores e, por conseguinte, resultam em níveis de pobreza distintos. De acordo com Lima (1980), é desfeita a relação causal direta entre educação e salários, tão evidente na Teoria do Capital Humano. A Teoria da Segmentação ${ }^{25}$ se preocupa com o local em que a renda é gerada: o posto de trabalho. Utiliza-se uma dummy para identificar, a partir do coeficiente estimado, a diferença entre a probabilidade de ser pobre da categoria tomada como base (agrícola) e as famílias pluriativas e não agrícolas $\left(\right.$ Pluriatividade $\left._{i}\right)$ e (fam_nagricola ${ }_{i}$ ). Espera-se que famílias que estejam ocupadas em atividades agrícolas sejam mais propensas a serem pobres do que aquelas ocupadas em atividades não agrícolas e, ou, aquelas classificadas como pluriativas ${ }^{26}$. Adicionalmente, foram utilizadas dummies (Sudeste $\left.{ }_{i}\right),\left(\right.$ Centro $\left._{i}\right)$, $\left(\right.$ Norte $\left._{i}\right)$ e $\left(S u l_{i}\right)$, para captar a segmentação regional devido à heterogeneidade brasileira, em que a variável-controle é o Nordeste. Procura-se, a partir dos coeficientes estimados, verificar se as políticas de combate à pobreza devem possuir abrangência regional.

Para mensuração de uma das mais importantes variáveis responsáveis pela desigualdade de rendimento no rural, a posição na ocupação, utilizam-se dummies para identificar se as pessoas são empregadoras, trabalham por conta própria ou são empregados. Espera-se um sinal positivo para ambas as dummies, (Empregador ${ }_{i}$ ) e (cont_propria $a_{i}$ ), revelando que, em comparação com os empregados, posição tomada como base, essas duas posições na ocupação têm menos chances de ser pobre ${ }^{27}$.

Como proxy de infraestrutura nos setores estratégicos da economia (transporte, energia, comunicação, saúde e saneamento), foram utilizadas dummies para identificar as subdivisões do meio rural, (rural_ext_urbana $\left.a_{i}\right)$, $\left(r u r a l \_a g l o \_i s o \_p o v_{i}\right)$, (rural_exc_aglo $o_{i}$ ), construídas a partir de critérios como tamanho (número de domicílios), existência de serviços e contiguidade ${ }^{28}$. Espera-se que, quanto mais próximo da área urbana, menores as chances de ser pobre.

\footnotetext{
${ }^{25}$ Segundo Langoni (1973), Thurow (1975) e Gandra (2002), o ramo de atividade (atividades agrícolas e não agrícolas), a região geográfica e o setor censitário (rural e urbano) são também variáveis determinantes no processo de seleção e rendimentos dos trabalhadores, revelando a segmentação de mercado.

${ }^{26}$ Para mais informações, ver Barros et al. (2007), Corrêa (1998) e Santos et al. (2010).

27 Segundo Ney e Hoffmann (2003), ao incluir na regressão apenas a posição na ocupação como proxy para o capital físico, é possível captar claramente parte do efeito da área no rendimento agrícola. Mas boa parte desse efeito não será captada, pois há uma enorme desigualdade na distribuição da posse da terra dentro de cada posição na ocupação.

${ }^{28}$ Para a definição dos desdobramentos do meio rural brasileira vide Graziano e Del Grossi (1999).
} 
O modelo logit é estimado por Máxima Verossimilhança, através do Data Analysis and Statistical Software (STATA). Cada coeficiente estimado pela regressão logística fornece estimativa do logaritmo natural $(l n)$ das odds ratios ajustado para todas as variáveis do modelo, possibilitando a estimação direta através da exponenciação do coeficiente. $\mathrm{O}$ estudo da magnitude das odds ratios $(\mathrm{OR})$ do parâmetro para Educação ou ocupações não agrícolas, por exemplo, permite inferir se o investimento em capital humano e em atividades não agrícolas está diminuindo a probabilidade de ser pobre ao longo dos anos. Busca-se também identificar se as transformações em curso no meio rural têm alterado o perfil da pobreza, por meio dos valores e sinais dos parâmetros $\beta_{2}, \beta_{3}, \beta_{4}, \beta_{5}, \beta_{6}$ e $\beta_{7}$ da equação (1).

\section{Resultados e discussão}

\subsubsection{Proporção, intensidade e severidade da pobreza no meio rural brasileiro}

$\mathrm{Na}$ Tabela 1 constam os resultados do índice FGT para a população rural brasileira, em que se utilizou o somatório da renda de todas as fontes para os cálculos pertinentes $^{29}$. Os índices FGT(0), FGT(1) e FGT(2) variam de 0 a 1 , ou $0 \%$ a $100 \%$. Em relação ao FGT(0), tem-se que 0 significa que não existe nenhum pobre, e 1 que todos da amostra são pobres. No que concerne ao FGT(1), o valor encontrado significa quão distantes os indivíduos considerados pobres estão da linha de pobreza, identificando o montante da renda necessária para sair dessa condição. Por exemplo, se o valor verificado é de 0,30 ou $30 \%$, e a linha de pobreza estimada é de $\mathrm{R} \$ 100,00$, significa que em média os indivíduos precisam de um acréscimo de trinta reais na sua renda para ultrapassarem a linha de pobreza. A medida FGT(2) é, normalmente, tratada como medida de desigualdade entre os pobres. Pode variar de 0 a 1, em que valores próximos a 1 indicam maior desigualdade entre aqueles classificados como pobres.

Em 2001, no Sudeste, a proporção de pobres no meio rural era de 53\%, FGT(0). Mais precisamente, 3.314.374 pessoas, entre 6.253.537 residentes nessa região, foram consideradas pobres. O valor FGT(1) indica que a renda auferida era 50,8\% menor do que a linha de pobreza estabelecida no Sudeste, no valor de $\mathrm{R} \$ 64,76$ por pessoa. Em média, se cada pessoa classificada como pobre recebesse cerca de trinta reais para complementar sua renda não haveria pobreza no Sudeste. O valor FGT(2) para o Sudeste é de 0,502, que reflete a desigualdade entre os pobres. Em 2012, a proporção de pobres caiu, passando para 35,7\%, em uma população de 5.589.914 do meio rural. A distância desses indivíduos à linha de pobreza foi de $32,2 \%$, indicando que em média era necessário

29 A PNAD possui informações quanto à renda do trabalho principal, de todos os trabalhos e de todas as fontes de renda. Mais informações podem ser consultadas no Dicionário de Pessoas, da PNAD. 
um acréscimo de quarenta e três reais para se atingir a linha de pobreza, de $\mathrm{R} \$ 135,59$. Em relação à desigualdade entre os pobres, verificou-se o valor de $31,2 \%$. A queda observada nos índices de 2001 para 2012 foi expressiva para FGT(0), FGT(1) e FGT(2), ou seja, 32,63\%, 36,69\% e 37,76\%, respectivamente. É possível verificar, pelos resultados de cada ano apresentados, que essa queda foi suave e contínua.

Em 2001, no Centro-Oeste a proporção de pobres no meio rural era de 56,4\%, FGT(0), de um total de 1.603 .903 pessoas residentes nessa região. Os indivíduos considerados pobres estavam distantes da linha de pobreza em aproximadamente 54,3\%, FGT(1). E o hiato da pobreza ao quadrado era de 53,7\%, FGT(2). Em 2012, das 1.459.034 pessoas residentes em áreas rurais da região, cerca de 35,10\% possuíam rendimento abaixo da linha de pobreza e elas estavam, em média, distantes da linha de pobreza em $32,7 \%$. No que diz respeito à severidade, FGT(2), o índice de desigualdade apresentado foi de 31,9\%. Constatou-se queda considerável nas três medidas de pobreza. Por exemplo, para a proporção de pobres a redução foi de 37,70\%, já nos demais índices as reduções foram, respectivamente, de 39,81\% e 40,55\% para FGT(1) e FGT(2).

Em 2001 não foi possível calcular os índices de pobreza para o Norte, pois a PNAD não cobria essa região do Brasil até 2003. Em 2004, a proporção de pobres no meio rural era de $50,06 \% \mathrm{FGT}(0)$, dos 4.182 .984 de pessoas residentes na região em foco, especificamente, 2.094.001 pessoas em estado de privação no Norte do país. Em média, esses pobres encontravam-se distantes $48,2 \%$ da linha de pobreza, significando que a renda auferida média era quase a metade da linha de pobreza estabelecida para o Norte, R\$ 62,47. O valor do índice FGT(2) para o Norte é de 47,5\%, que reflete a elevada desigualdade entre os pobres. Em 2012, a proporção de pobres decresceu, passando para 40,2\% dos 4.124.102 residentes nessa região. A renda necessária para alcançar a linha de pobreza de $\mathrm{R} \$ 98,52$ era de 38,9\% desse valor. Em relação à desigualdade entre os pobres, o índice apresentado foi de 38,5\%. A queda observada nos índices FGT(0), FGT(1) e FGT(2) foi de 20,66\%,19,29\% e 18,98\%, respectivamente. É interessante destacar que a variação apresentada reflete uma comparação de 2004 a 2012 e, dessa forma, representa resultados inferiores aos encontrados nas outras regiões, em que se analisa período de queda contínua nos indicadores.

Em 2001, no Sul do Brasil, a proporção de pobres no meio rural era de 50,5\%, FGT(0), ou seja, 2.393.532 das 4.737 .689 pessoas residentes nessa região eram consideradas pobres. Os indivíduos considerados pobres estavam distantes da linha de pobreza em aproximadamente $48,8 \%$, FGT(1), e o hiato da pobreza ao quadrado era de 48,2\% FGT(2). No fim da década, ocorre queda expressiva nas três medidas de pobreza, por exemplo, para a proporção de pobres a redução foi de $37,87 \%$, enquanto nos demais índices as reduções foram, respectivamente, de 39,25\% e 39,55\% para FGT(1) e FGT(2). Em 2012, das 4.155 .980 pessoas residentes em áreas rurais da região, cerca de 31,4\% estavam abaixo da linha de pobreza, e estas estavam, em média, distantes da linha de pobreza em $29,6 \%$, e o índice de desigualdade, FGT(2), foi de $29,2 \%$. 
Tabela 1 - Classe FGT das medidas de pobreza, 2001 a 2012, para o somatório de todas fontes de renda

\begin{tabular}{|c|c|c|c|c|c|c|c|c|c|c|c|c|}
\hline FGT & 2001 & 2002 & 2003 & 2004 & 2005 & 2006 & 2007 & 2008 & 2009 & 2011 & 2012 & Var. 2001-2012(\%) \\
\hline \multicolumn{13}{|l|}{ Região Sudeste } \\
\hline FGT(0) Prop. Pobres & 0,53 & 0,463 & 0,46 & 0,426 & 0,447 & 0,416 & 0,418 & 0,401 & 0,389 & 0,371 & 0,357 & $-32,63 \%$ \\
\hline FGT(1) Hiato de Pobreza & 0,508 & 0,436 & 0,435 & 0,397 & 0,406 & 0,376 & 0,383 & 0,368 & 0,361 & 0,349 & 0,322 & $-36,69 \%$ \\
\hline FGT(2) Desig. na Pobreza & 0,502 & 0,428 & 0,425 & 0,387 & 0,391 & 0,366 & 0,375 & 0,359 & 0,354 & 0,342 & 0,312 & $-37,76 \%$ \\
\hline \multicolumn{13}{|l|}{ Região Centro-Oeste } \\
\hline FGT(0) Prop. de Pobres & 0,564 & 0,467 & 0,483 & 0,455 & 0,471 & 0,444 & 0,44 & 0,428 & 0,416 & 0,368 & 0,351 & $-37,70 \%$ \\
\hline FGT(1) Hiato de Pobreza & 0,543 & 0,446 & 0,458 & 0,431 & 0,437 & 0,403 & 0,411 & 0,391 & 0,383 & 0,36 & 0,327 & $-39,81 \%$ \\
\hline FGT(2) Desig. na Pobreza & 0,537 & 0,438 & 0,45 & 0,422 & 0,429 & 0,392 & 0,404 & 0,381 & 0,374 & 0,353 & 0,319 & $-40,55 \%$ \\
\hline \multicolumn{13}{|l|}{ Região Norte } \\
\hline FGT(0) Prop. de Pobres & - & - & - & 0,506 & 0,506 & 0,475 & 0,48 & 0,442 & 0,422 & 0,433 & 0,402 & $-20,66 \%$ \\
\hline FGT(1) Hiato de Pobreza & - & - & - & 0,482 & 0,483 & 0,452 & 0,467 & 0,425 & 0,408 & 0,416 & 0,389 & $-19,29 \%$ \\
\hline FGT(2) Desig. na Pobreza & - & - & - & 0,475 & 0,476 & 0,447 & 0,464 & 0,42 & 0,405 & 0,412 & 0,385 & $-18,98 \%$ \\
\hline \multicolumn{13}{|l|}{ Região Sul } \\
\hline FGT(0) Prop. de Pobres & 0,505 & 0,444 & 0,422 & 0,42 & 0,41 & 0,394 & 0,386 & 0,358 & 0,361 & 0,335 & 0,314 & $-37,87 \%$ \\
\hline FGT(1) Hiato de Pobreza & 0,488 & 0,426 & 0,402 & 0,402 & 0,393 & 0,371 & 0,373 & 0,343 & 0,349 & 0,316 & 0,296 & $-39,25 \%$ \\
\hline FGT(2) Desig. na Pobreza & 0,482 & 0,419 & 0,394 & 0,394 & 0,386 & 0,364 & 0,369 & 0,338 & 0,345 & 0,312 & 0,292 & $-39,55 \%$ \\
\hline \multicolumn{13}{|l|}{ Região Nordeste } \\
\hline FGT(0) Prop. de Pobres & 0,606 & 0,545 & 0,555 & 0,523 & 0,504 & 0,515 & 0,462 & 0,45 & 0,455 & 0,432 & $-28,69 \%$ & \\
\hline FGT(1) Hiato de Pobreza & 0,568 & 0,49 & 0,487 & 0,461 & 0,448 & 0,426 & 0,433 & 0,412 & 0,396 & 0,395 & 0,375 & $-34,01 \%$ \\
\hline FGT(2) Desig. na Pobreza & 0,554 & 0,468 & 0,46 & 0,44 & 0,43 & 0,407 & 0,419 & 0,398 & 0,383 & 0,384 & 0,362 & $-34,74 \%$ \\
\hline \multicolumn{13}{|l|}{ Brasil* } \\
\hline FGT(0) Prop. de Pobres & 0,586 & 0,52 & 0,521 & 0,506 & 0,512 & 0,506 & 0,499 & 0,458 & 0,456 & 0,443 & 0,417 & $-28,92 \%$ \\
\hline FGT(1) Hiato de Pobreza & 0,548 & 0,475 & 0,47 & 0,452 & 0,447 & 0,43 & 0,431 & 0,404 & 0,395 & 0,387 & 0,363 & $-33,70 \%$ \\
\hline FGT(2) Desig. na Pobreza & 0,535 & 0,457 & 0,449 & 0,434 & 0,428 & 0,408 & 0,415 & 0,389 & 0,38 & 0,373 & 0,348 & $-34,92 \%$ \\
\hline
\end{tabular}

Fonte: Elaboração própria.

*Para o Brasil, a linha oficial considerada pelo governo foi de $\mathrm{R} \$ 140,00$ em valores de 2011, as correções foram realizadas pelo IPCA-IBGE. 
Apesar do crescimento econômico nos anos de 2000, esse não é o fator principal para a redução da pobreza. O período analisado abarca os anos em que se aumentou o número de transferências de renda ${ }^{30}$. Nesse sentido, é possível verificar que a expansão das políticas públicas de transferências de renda nas regiões com menor grau de desenvolvimento socioeconômico do país, como as rurais, estão sendo eficazes. De fato, verifica-se queda contínua da pobreza em todas as regiões do Brasil, mesmo diante dos efeitos econômicos negativos decorrentes da crise internacional desde 2008.

Além do crescimento econômico e do aumento das transferências, estudos têm apontado a expansão do sistema de aposentadoria rural e as mudanças no mercado de trabalho não agrícola como importantes para a melhoria do quadro de pobreza no meio rural. Mais especificamente, Schneider (2003) e Rocha (2006) mostraram os impactos positivos advindos da pluriatividade. Nesses trabalhos, afirma-se que a junção de atividades agrícolas e não agrícolas nas famílias evidencia uma boa estratégia para baixar a vulnerabilidade dessas famílias no que concerne à pobreza ${ }^{31}$. Ferreira e Souza (2007) destacaram a importância da previdência rural para a diminuição da pobreza rural. A presença do idoso nas famílias reduz o efeito da vulnerabilidade ${ }^{32}$, de modo que esse idoso passou a ocupar, muitas das vezes, a posição de provedor da família. Rocha (2008), Hoffmann (2006) e Resende e Oliveira (2008) revelaram a importância das transferências de renda, que fazem que famílias tenham garantia de renda mínima, que vêm contribuir, principalmente, em períodos de seca, enchentes etc. Essas transferências, de certa forma, atuam como diminuição do risco das atividades de agricultura familiar.

\footnotetext{
30 O Programa Bolsa Família tem três tipos de benefícios: o Básico, o Variável e o Variável Vinculado ao Adolescente. O Benefício Básico, de $\mathrm{R} \$ 77,00$ (setenta e sete reais), é pago às famílias consideradas extremamente pobres, aquelas com renda mensal de até $\mathrm{R} \$ 77,00$ (setenta e sete reais) por pessoa (pago às famílias mesmo que elas não tenham crianças, adolescentes ou jovens). De acordo com o Decreto $\mathrm{n}^{\circ} 7.494$ de 02/06/2011, a família terá direito a receber até 05 benefícios variáveis, conforme o seu perfil. $\mathrm{O}$ Benefício Variável, de $\mathrm{R} \$ 42,00$ (quarenta e dois reais), é pago às famílias pobres, aquelas com renda mensal de até $\mathrm{R} \$ 120,00$ (cento e vinte reais) por pessoa desde que tenham crianças e adolescentes de até 15 anos. Para gestantes o valor do benefício variável é de $\mathrm{R} \$ 35,00$ (trinta e cinco reais), uma por mês de gestação. Essas informações podem ser acessadas em: <http://www.mds.gov.br/falemds/perguntas-frequentes/bolsafamilia/beneficios/gestor/pbf-alteracao-no-valor-do-beneficio>.

${ }^{31}$ De acordo com Wood (2003) e Waterhouse (2009), existe relação entre pobreza e risco, em que a probabilidade de uma família entrar na pobreza depende das fontes de riscos que essa família enfrenta, da posse de ativos e da capacidade de gerenciar esses riscos. Riscos como quebra de safra agrícola e de flutuações de preços formam o grau de vulnerabilidade.

32 Para Bourdieu (1989), vulnerabilidade social é um conceito multidimensional que se refere à condição de indivíduos ou grupos em situação de fragilidade, que os tornam expostos a riscos e a níveis significativos de desagregação social. Relaciona-se ao resultado de qualquer processo acentuado de exclusão, discriminação ou enfraquecimento de indivíduos ou grupos, provocados por fatores, como pobreza, crises econômicas, nível educacional deficiente, localização geográfica precária e baixos níveis de capital social, humano, ou cultural, entre outros, que gera fragilidade dos atores no meio social.
} 
Para Neder et al. (2011), esses resultados permitem estabelecer uma avaliação das áreas rurais no Brasil, em termos de efetividade do combate à pobreza. Para Marinho et al. (2011), apesar das diversas críticas aos programas assistenciais do governo à população carente, estes ainda são geradores de maior impacto distributivo focado na população mais necessitada. Em dezembro de 2009, o número de beneficiados pelos diversos programas federais de garantia de renda chegou a 42.581.308; destes, 12.370.915 benefícios são referentes ao PBF. Em outras palavras, o cenário de pobreza rural tem-se mostrado sensível aos esforços do Governo de combate à pobreza. Entretanto, ainda é muito expressivo o número de pobres no meio rural. No começo da série analisada, encontra-se mais da metade da população do meio rural na pobreza. Mesmo contabilizando o recebimento de todas as transferências, aposentadoria rural e demais fontes de renda, esse número ainda continua expressivo até 2012, em que nenhuma região está abaixo dos $30 \%$, considerando o FGT(0).

Próximas às medidas encontradas para o Nordeste, encontram-se as medidas da Região Norte. Essas duas regiões foram as responsáveis pela menor queda da pobreza. Verificou-se, no Nordeste, queda de apenas 28,69\%, entre 2001 e 2012. Quanto ao Norte, a comparação entre 2001 e 2012 não é possível devido à disponibilidade dos dados. Porém, entre 2004 e 2012 a queda também é pouco expressiva, cerca de 20,66\%.

No Sul e Sudeste, o cenário da pobreza é o menos grave em relação às demais regiões. Segundo Waquil (2011), principalmente na Região Sul, perceberam-se cada vez mais as fortes relações do setor agrícola com os demais setores da economia, consolidando complexos agroindustriais, bem como intensas relações entre o rural e o urbano e a ampliação das atividades não agrícolas nas áreas rurais. Essa constatação permite inferir que as atividades não agrícolas têm contribuído para melhorar a situação adversa em que se encontrava o pequeno agricultor, no que concerne às intempéries do setor agrícola.

Diante dos resultados apresentados, constatou-se que, independentemente da região do país e do índice FGT considerado FGT $(0,1,2)$, há tendência de redução da pobreza em todo o país para o meio rural.

\subsubsection{Resultados da estimação dos determinantes da pobreza no meio rural}

Nesta seção, busca-se compreender possíveis causas da pobreza no meio rural brasileiro, ampliando o espectro de visão dos índices FGT. Cabe reforçar que a análise empregada é estática comparativa, que por sua vez não permite o controle da persistência da pobreza. Permite entender se o impacto desses determinantes sofreu alterações no período de 2001 a 2012, propiciando um perfil da pobreza robusto. 
Algumas características são comuns tanto para os indivíduos que residem no meio urbano quanto no meio rural, como a incidência maior para pessoas negras, mulheres e residentes na região nordeste. Porém, no meio rural também chama atenção o tipo de atividade exercida. Por exemplo, constatou-se que os indivíduos ao exercerem alguma atividade não agrícola como principal atividade econômica apresentaram, em sua maioria, menor probabilidade de ser pobre. Ademais, a distância do meio rural às cidades e o grau de urbanização do rural são também importantes para a mensuração da intensidade da probabilidade de ser pobre. Não obstante, nesta pesquisa é dada atenção especial à capacidade de as transformações em voga no meio rural alterarem o perfil da pobreza no meio rural.

$\mathrm{Na}$ Tabela 2, apresenta-se a evolução da razão de chances ou razão de possibilidades, odds ratios (OR) de cada variável, de forma separada, no período de 2001 a 2012. Neste estudo, essa razão reflete a possibilidade de ser definido como pobre, dividida pela probabilidade da não ocorrência do mesmo evento (de não ser pobre) para aqueles que possuem determinadas características ${ }^{33}$. A escolha da odds ratio, em detrimento dos coeficientes estimados, se deve ao fato de que os últimos contemplam apenas a variação no logit estimado (logaritmo das chances favoráveis) para uma variação unitária do regressor, tudo mais constante. A interpretação dos coeficientes dessa forma dificulta a comparação dos grupos pobres e não pobres $^{34}$.

O ajuste global do modelo foi verificado pela estatística razão de verossimilhança que se mostrou significativa a $1 \%$. Portanto, rejeita-se a hipótese de nulidade conjunta de todos os coeficientes do modelo, exceto o da constante, o que indica que o modelo se ajusta adequadamente aos dados. A análise de significância individual dos coeficientes estimados indica que a maior parte dos coeficientes é estatisticamente significativa a $1 \%$.

A partir da Tabela 2, verifica-se que a chance de uma pessoa estar pobre é cerca de 70\%, média no período de 2001 a 2012, menor numa família chefiada por homem do que por mulher no período analisado. Em 2001, as chances de uma pessoa ser pobre é 88,5\% menor em uma família chefiada por homem do que em uma família cuja pessoa de referência é a mulher. E 2012, essa probabilidade caiu para 55\%. Questões culturais são mais arraigadas no meio rural, em que se prevalece o modelo patriarcal. Nesse modelo, o papel da mulher é de boa esposa e boa mãe, e ao homem cabe o papel de provedor da família ${ }^{35}$.

\footnotetext{
${ }^{33}$ A interpretação de variáveis quantitativas é feita pelo incremento de uma unidade e pela comparação da categoria analisada com a categoria base. Já a interpretação para uma variável dummy é dada pela reação de uma categoria com outra.

${ }^{34} \mathrm{O}$ odds ratio de uma variável contínua representa uma média dos odds nos diversos níveis desta variável.

${ }^{35}$ Mais informações, vide Patriarcha e Pastor (2011).
} 
É possível verificar também que famílias chefiadas por pessoas pardas e brancas possuem menos chances em ser pobre em relação às chefiadas por negros, com cerca de $10 \%$ e $20 \%$ ao longo dos anos. Cellini et al. (2008), em uma compilação dos estudos sobre pobreza realizados no EUA, verificaram que cor e gênero são variáveis importantes para a entrada e permanência na pobreza. Para essas autoras, as pesquisas demonstram que normalmente negros e famílias chefiadas por mulheres experimentam a pobreza ininterrupta por mais anos. Santos et al. (2010) também verificaram, no meio rural brasileiro, discriminação no mercado de trabalho. Em que pessoas com igual Educação e experiência recebem menos por ser mulher e, ou, negro. A partir dos resultados apresentados por esta pesquisa, foi possível inferir que a discriminação por cor da pele e gênero constitui fenômeno de países desenvolvidos e em desenvolvimento. Em outras palavras, é preciso mais que desenvolvimento econômico para mudar esse quadro, passando por uma reforma cultural com o auxílio de leis trabalhistas mais preparadas para fiscalizar e coibir esse tipo de discriminação.

No que concerne às variáveis de núcleo familiar, verifica-se que, em todos os anos, a presença de idoso do sexo masculino na família aumenta as chances de experimentar a pobreza, cerca de $228 \%$ em 2001 e $124 \%$ em 2012. Com relação à presença de idoso do sexo feminino, as chances não elevam substancialmente. Essa divergência de valores pode ser devida ao fato de se considerar idosa a partir dos 55 anos, idade em que a mulher do campo pode se aposentar. Para os homens, essa idade é de 60 anos. Em 2001, verificou-se que, em famílias em que pelo menos um membro é mulher acima de 55 anos, as chances de ser pobre são cerca de $76 \%$ superiores em famílias que não possuem. Nesse ano, é que se verifica o maior diferencial. Em 2012, observa-se que em famílias com mulher acima de 55 anos as chances de ser pobre são 11,3\% maiores do que nas famílias que não possuem.

A partir desses resultados, pode-se inferir que é preciso ainda maior zelo com as famílias que possuem idosos, abarcando essa demanda nos demais programas de transferência de renda. Ademais, devido ao aumento da expectativa de vida da população brasileira e à diminuição da natalidade (revelando uma inversão da pirâmide etária no meio rural), é preciso rever as transferências de renda que geralmente são voltadas para as famílias com crianças, como Bolsa Família e Brasil Carinhoso. Esses resultados vão de encontro aos resultados de Ferreira e Souza (2007) e Buainain et al. (2010), que acreditam que o idoso rural passa de uma situação de fator de vulnerabilidade para de provedor da família, devido à aposentadoria rural. Resultados como os de Marinho e Araújo (2010) reafirmaram os resultados apresentados neste artigo. 
Tabela 2 - Determinantes da pobreza no meio rural

\begin{tabular}{|c|c|c|c|c|c|c|c|c|c|c|c|}
\hline Variáveis & 2001 & 2002 & 2003 & 2004 & 2005 & 2006 & 2007 & 2008 & 2009 & 2011 & 2012 \\
\hline Constante & $10,32 * * *$ & $1,255 * * *$ & $1,431 * * *$ & $1,281 * * *$ & $1,427 * * *$ & $1,231 * * *$ & $1,845 * * *$ & $1,429 * * *$ & $1,837 * * *$ & $0,431 * * *$ & $1,639 * * *$ \\
\hline Gênero (Masculino) & $0,115 * * *$ & $0,279 * * *$ & $0,304 * * *$ & $0,279 * * *$ & $0,225 * * *$ & $0,284 * * *$ & $0,313 * * *$ & $0,350 * * *$ & $0,272 * * *$ & $0,473 * * *$ & $0,459 * * *$ \\
\hline Cor/Raça - Parda & $0,890 * * *$ & $0,912 * * *$ & $0,872 * * *$ & $0,987 * * *$ & $0,926 * * *$ & $1,305 * * *$ & $0,892 * * *$ & $0,997 * * *$ & $0,964 * * *$ & $0,859 * * *$ & $0,863 * * *$ \\
\hline Cor/Raça - Brancas e Amarelas & $0,799 *$ & $0,858 * * *$ & $0,862 * * *$ & $0,990 * *$ & $1,074 * * *$ & $1,261 * * *$ & $0,910 * * *$ & $0,813 * * *$ & $0,783 * * *$ & $0,854 * * *$ & $0,794 * * *$ \\
\hline Idoso Homem na Família & $3,288 * * *$ & $2,387 * * *$ & $2,382 * * *$ & $2,529 * * *$ & $2,926 * * *$ & $2,613 * * *$ & $2,143 * * *$ & $2,547 * * *$ & $2,785 * * *$ & $2,090 * * *$ & $2,246 * * *$ \\
\hline Idoso Mulher na Família & $1,763 * * *$ & $1,240 * * *$ & $1,370 * * *$ & $1,407 * * *$ & $1,306 * * *$ & $1,376^{* * *}$ & $1,250 * * *$ & $1,393 * * *$ & $1,183 * * *$ & $1,346 * * *$ & $1,113 * * *$ \\
\hline Criança de 11-17 anos na Fam. & $0,996 \mathrm{NS}$ & $0,784 * * *$ & $0,797 * * *$ & $0,708 * * *$ & $0,885 * * *$ & $0,887 * * *$ & $0,862 * * *$ & $0,836 * * *$ & $0,840 * * *$ & $0,956 * * *$ & $0,905 * * *$ \\
\hline Criança de 0-10 anos na Fam. & $0,967 * * *$ & $1,348 * * *$ & $1,008 * * *$ & $0,994 * * *$ & $1,093 * * *$ & $1,097 * * *$ & $0,863 * * *$ & $1,018 * * *$ & $0,815 * * *$ & $0,874 * * *$ & $0,860 * * *$ \\
\hline Pai ou Mãe solteiros & $1,624 * * *$ & $1,748 * * *$ & $1,926 * * *$ & $1,824 * * *$ & $1,617 * * *$ & $1,843 * * *$ & $1,779 * * *$ & $1,851 * * *$ & $1,650 * * *$ & $2,071 * * *$ & $1,701 * * *$ \\
\hline Casal & $0,864 * * *$ & $0,763 * * *$ & $0,734 * * *$ & $0,827 * * *$ & $0,811 * * *$ & $0,799 * * *$ & $0,982 * * *$ & $0,833 * * *$ & $0,871 * * *$ & $0,862 * * *$ & $0,912 * * *$ \\
\hline Família Pluriativa & $0,864 * * *$ & $0,891 * * *$ & $0,893 * * *$ & $0,885 * * *$ & $0,976 * * *$ & $0,849 * * *$ & $0,753 * * *$ & $0,864 * * *$ & $0,730 * * *$ & $0,741 * * *$ & $0,783 * * *$ \\
\hline Família não-agrícola & $0,465 * * *$ & $0,156 * * *$ & $0,150 * * *$ & $0,143 * * *$ & $0,177 * * *$ & $0,126 * * *$ & $0,125 * * *$ & $0,120 * * *$ & $0,066 * * *$ & $0,083 * * *$ & $0,074 * * *$ \\
\hline Educação em anos de e & $0,863 * * *$ & $0,901 * * *$ & $0,953 * * *$ & $0,972 * * *$ & $0,953 * * *$ & $0,950 * * *$ & $0,968 * * *$ & $0,941 * * *$ & $0,965 * * *$ & $0,952 * * *$ & $0,970 * * *$ \\
\hline imiar da Educação & $0,678 * * *$ & $0,804 * * *$ & $0,867 * * *$ & $1,030 * * *$ & $0,888 * * *$ & $0,971 * * *$ & $0,941 * * *$ & $1,013 * * *$ & $0,964 * * *$ & $0,948 * * *$ & $0,971 * * *$ \\
\hline Empregador & $0,075 * * *$ & $0,220 * * *$ & $0,221 * * *$ & $0,181 * * *$ & $0,129 * * *$ & $0,100 * * *$ & $0,086 * * *$ & $0,062 * * *$ & $0,076 * * *$ & $0,112 * * *$ & $0,052 * * *$ \\
\hline Conta-própria & $0,291 * * *$ & $0,656 * * *$ & $0,623 * * *$ & $0,489 * * *$ & $0,599 * * *$ & $0,438 * * *$ & $0,346 * * *$ & $0,294 * * *$ & $0,302 * * *$ & $0,270 * * *$ & $0,322 * * *$ \\
\hline Sudeste & $0,570 * * *$ & $0,689 * * *$ & $0,557 * * *$ & $0,494 * * *$ & $0,674 * * *$ & $0,433 * * *$ & $0,441 * * *$ & $0,493 * * *$ & $0,483 * * *$ & $0,330 * * *$ & $0,317 * * *$ \\
\hline Centro & $0,388 * * *$ & $0,397 * * *$ & $0,370 * * *$ & $0,261 * * *$ & $0,400 * * *$ & $0,426 * * *$ & $0,310 * * *$ & $0,416 * * *$ & $0,438 * * *$ & $0,181 * * *$ & $0,213 * * *$ \\
\hline Norte & - & - & - & $0,402 \mathrm{NS}$ & $0,375 \mathrm{NS}$ & $0,394 \mathrm{NS}$ & $0,3541 \mathrm{NS}$ & $0,392 \mathrm{NS}$ & $0,467 \mathrm{NS}$ & $0,361 \mathrm{NS}$ & $0,3366 \mathrm{NS}$ \\
\hline Sul & $0,588 * * *$ & $0,717 * * *$ & $0,586 * * *$ & $0,472 * * *$ & $0,580 * * *$ & $0,648 * * *$ & $0,421 * * *$ & $0,575 * * *$ & $0,466 * * *$ & $0,449 * * *$ & $0,430 * * *$ \\
\hline Aglom & $0,595 * * *$ & $0,659 * * *$ & $0,482 * * *$ & $0,849 * * *$ & $0,534 * * *$ & $0,745 * * *$ & $0,970 * * *$ & $0,926 * * *$ & $0,810 * * *$ & $1,913 * * *$ & $0,403 * * *$ \\
\hline Aglo. rural, isolado, povoado & $0,490 * * *$ & $0,937 * * *$ & $0,819 * * *$ & $0,932 * * *$ & $0,910 * * *$ & $0,990 * * *$ & $0,821 * * *$ & $1,123 * * *$ & $0,905 * * *$ & $3,455 \mathrm{NS}$ & $0,691 * * *$ \\
\hline Zona rural exclusive aglo., rural & $0,550 * * *$ & - & $0,857 * * *$ & - & - & - & - & - & - & $4,361 \mathrm{NS}$ & - \\
\hline Aglo. rural, isolado, outros aglo. & - & $1,294 * * *$ & - & $0,696 * * *$ & $0,677 * * *$ & - & - & $1,429 * * *$ & - & 9,959NS & $1,596 * * *$ \\
\hline Razão de Verossimilhança & $-1119436,3$ & $-1548005,3$ & $-1539401,4$ & $-1471221,9$ & $-1638385,9$ & $-1506592,2$ & $-1325778,9$ & $-1179875,8$ & $-1157266,4$ & $-1121546,9$ & $-111847,0$ \\
\hline Prob, > chi2 & 0,00000 & 0,00000 & 0,00000 & 0,00000 & 0,00000 & 0,00000 & 0,00000 & 0,00000 & 0,00000 & 0,00000 & 0,00000 \\
\hline Num. obs & 10.717 & 12.111 & 11.938 & 14.122 & 14.585 & 14.334 & 13.518 & 13.228 & 13.341 & 10.766 & 10.717 \\
\hline Pop. Considerada & 6.035 .520 & 6.038 .253 & 5.951 .302 & 6.823 .639 & 6.997 .417 & 6.859 .322 & 6.721 .589 & 6.749 .540 & 6.776 .427 & 5.949 .533 & 6.035 .520 \\
\hline
\end{tabular}

onde: *** significativas a 1\%; ** significativas a 5\%; *significativas a 10\%; NS não significativas.

Fonte: Resultados da pesquisa. 
Antes de 2008, o fato de ter criança entre 0 e 10 anos aumentava as chances de ser pobre em cerca de $10 \%$. A partir de 2008 , as chances de ser pobre não aumentam para as famílias que possuem crianças de 0 a 10 anos. Considerando crianças entre 11 e 17 anos, em nenhum dos anos analisados, tem-se o aumento da probabilidade de a família ser pobre. Assim como verificado na análise para famílias com idosos, a presença de criança requer cuidados especiais, já que as crianças não podem auferir renda através do trabalho e, portanto, era esperado o aumento das chances de ser pobre. Em razão da presença de crianças na família, os programas de transferência de renda priorizam as famílias com crianças pequenas. Uma possível explicação seria que as transferências de renda têm funcionado como microcrédito, ampliando substancialmente a renda dessas famílias. Não obstante, esses resultados precisam ser averiguados nos próximos anos ${ }^{36}$.

Famílias, cuja pessoa de referência possua cônjuge, têm mais chances de não experimentarem a pobreza. Em 2002, verificou-se que as famílias cuja pessoa de referência possua cônjuge, apresentam menos de $24 \%$ de chances de ser pobre em relação a outros arranjos sociais. Espera-se que a família com maior estrutura familiar possa superar a pobreza, tanto pela possibilidade de possuir mais adultos trabalhando (mãe ou pai), quanto de dividir os custos da criação dos filhos, bem como por questões psicológicas. Em 2001, por exemplo, em famílias cuja pessoa de referência seja solteira, as chances de ser pobre são 62,4\% a mais do que em outros arranjos sociais. Em 2011, o valor chega a cerca de 107\%. Para Layte e Whelan (2003), a composição da estrutura familiar é importante para explicar a pobreza ao longo dos anos. Destacam-se também os episódios de divórcio que aumentam o risco de entrar na pobreza proporcionada pela instabilidade emocional e financeira inerente à separação. Outros eventos significativos associados com a entrada de pobreza incluem transições de famílias cujo chefe possua cônjuge para famílias cuja pessoa de referência seja mulher solteira. Para Rodrigues et al. (1999), a família é uma célula estruturante da vida social que não permanece inalterada, tendo conhecido várias transformações nas suas formas tradicionais, designadamente com a passagem das formas de família alargada para formas de família nuclear, principalmente no contexto das sociedades ocidentais. Além da família nuclear, coexistem novas e outras formas de conjugabilidade e formas "atípicas", o que revela o caráter dinâmico da família e suas interferências no estado de pobreza das famílias.

As famílias não agrícolas possuem menos chances de serem pobres, assim como as famílias pluriativas em todo o período analisado. No meio rural, verifica-se o aumento de atividades não agrícolas em razão, principalmente, da expansão dos serviços públicos; ao aumento da demanda por Educação, Saúde e Transporte, entre outros bens e serviços; ao aumento da demanda por terras para uso não agrícola, por parte das empresas que não querem assimilar as externalidades negativas dos centros urbanos; e ao aumento da demanda da população urbana de alta renda por uma segunda residência, em busca de áreas de lazer. As atividades não agrícolas possuem regularidade de renda e, ou, salários para as pessoas

${ }^{36}$ Explicações de transferência de renda funcionando como microcrédito podem ser encontradas em Rocha (2006). 
envolvidas nesse setor; ao contrário das atividades agrícolas, que estão sujeitas a variações devido à sazonalidade e quebra de safra, entre outros problemas inerentes ao setor agrícola.

De acordo com Graziano e Del Grossi (2001), em 1998 o total das rendas não agrícolas do Brasil ultrapassou o montante das rendas agrícolas recebido pelos moradores rurais. Não obstante, em artigo mais recente, Del Grossi e Graziano (2006) verificaram que as ocupações agrícolas começaram a retomar sua importância, em que se observou a recuperação das rendas de origem agrícola. Segundo Del Grossi (2012), no período 2001/2009 a renda média da agricultura familiar cresceu $30 \%$ em termos reais, enquanto que a renda média brasileira cresceu $11 \%$. Mesmo com todas essas políticas voltadas para a agricultura, como Programa Nacional de Fortalecimento da Agricultura Familiar (PRONAF) e Plano Nacional de Reforma Agrária PNRA que foram responsáveis por aumentar a renda agrícola ${ }^{37}$, ainda é maior a pobreza para aqueles ocupados em atividades agrícolas. Pode-se inferir que o aumento da renda agrícola ainda não atingiu a camada inferior da distribuição da renda com a intensidade necessária para diminuir a probabilidade de ser pobre entre os setores, papel este que parece estar sendo melhor cumprido pelas transferências de renda que mudou a relação de probabilidade para famílias com crianças com idade inferior a 11 anos. De acordo com Soares et al. (2016), os municípios do Norte e Nordeste com investimentos mais expressivos do PRONAF estão, em sua maior parte, localizados nos conglomerados de baixa pobreza.

No que concerne à Educação, verifica-se que os anos de estudos contribuem para a redução da probabilidade de as famílias serem pobres. Ressalta-se que, para cada ano analisado, foi considerado o limiar da Educação pertinente às equações estimadas para encontrar o pico de mudança. De acordo com Helfand e Pereira (2011), a Educação está relacionada a todos os possíveis caminhos de superação da pobreza rural, todavia a Educação no meio rural se mantém defasada, tanto em quantidade quanto em qualidade em relação ao meio urbano ${ }^{38}$. Os investimentos na formação de capital humano podem contribuir para a saída da pobreza, por meio de uma gama de canais. A relação entre o nível educacional da força de trabalho agrícola e a produtividade pode assumir várias formas: aumentando a eficiência técnica e, assim, permitindo que os agricultores produzam mais com seu estoque disponível de fatores de produção; aumentando a eficiência alocativa, permitindo melhores decisões considerando o mix de insumos utilizados na produção; e também aumentando a probabilidade de adoção de novas tecnologias. Para Bane e Ellwood (1986), a Educação é importante determinante para a não entrada da pobreza.

\footnotetext{
37 Vide Del Grossi (2012) e Hespanhol (2014).

${ }^{38}$ Para esses autores, os benefícios de escolaridade podem ir além dos indivíduos que recebem a Educação e podem alcançar também suas famílias e comunidades. Weir e Knight (2000) sugeriram dois canais. Primeiro, a Educação pode gerar externalidades se as pessoas instruídas aumentarem a produtividade dos outros. Por exemplo, os primeiros a adotarem inovações podem ser os agricultores educados que demonstram o valor de novos insumos e técnicas para as pessoas menos instruídas. Em segundo lugar, a Educação, especialmente das meninas, pode ser associada à melhoria da saúde e da nutrição e à redução da fertilidade. Finalmente, a Educação é transmitida de uma geração para outra, diminuindo, assim, a probabilidade de propagação da pobreza entre as gerações.
} 
A posição na ocupação, como empregador, tem sido usada nos trabalhos como proxy de posse dos ativos, e por isso é esperado que essa categoria seja responsável por menores índices de pobreza. Em 2001, o fato de ser empregador reduz a probabilidade de ser pobre em $93 \%$ em relação aos empregados. Em 2012, essa variável reduz a probabilidade em 95\%. A probabilidade também é reduzida para os que trabalham por conta própria.

Pelos resultados encontrados, verifica-se que, quanto mais próximo do urbano, menos chances a família possui de experimentar a pobreza. As famílias que residem no aglomerado extensão urbana possuem menos chances de ser pobre em relação àquelas que residem em áreas rurais propriamente ditas. Mais uma vez, evidencia-se a vulnerabilidade do rural em termos de infraestrutura, pois esses lugares mais distantes do urbano são marcados pela falta de transportes, estradas não pavimentadas, falta de acesso à energia elétrica etc. Dercon e Krishnan (1998), usando dados coletados da Etiópia rural de 1989, 1994 e 1995 para avaliar os fatores determinantes das mudanças nos níveis de pobreza, detectaram que as famílias com maior capital humano e melhor acesso a estradas apresentaram menores taxas de pobreza. Para Marinho e Soares (2003), no Brasil o resultado de destaque é o efeito que a infraestrutura exerce sobre a redução da pobreza. Isso indica que investimentos em infraestrutura influenciam diretamente a trajetória temporal da pobreza no Brasil. Essa evidência empírica valida a ideia de que a infraestrutura tem sido fundamental para a sua redução. Albuquerque (1995), por meio de estudo de modelos de intervenção pública em situações de pobreza no Brasil, constatou também a importância do investimento em infraestrutura.

As dummies regionais nos mostram que a pobreza é menos pronunciada no CentroOeste. No outro extremo, as famílias que residem no Nordeste possuem maior probabilidade de experimentar a pobreza. De acordo com Maluf e Mattei (2011), destacam-se três fatores como determinantes da pobreza no Nordeste: a privação do acesso à água; a privação do acesso à terra; e a ocorrência sistemática das secas, fenômeno que acaba impondo diversas outras restrições, especialmente em termos de acesso ao trabalho. Para esses autores, na Região Sul o fenômeno da pobreza rural tem maior expressão também nas microrregiões onde predominam os latifúndios, destacando-se os campos de Guarapuava (PR), as regiões das Missões e da Campanha (RS) e o Planalto Serrano (SC). Em todos esses locais, verificou-se um fenômeno correlacionado: as microrregiões com maior concentração de terras são exatamente aquelas que apresentam os maiores índices de pobreza rural.

\section{Considerações Finais}

Nos últimos anos, verificou-se forte mudança no meio rural, marcada principalmente pela expansão das ocupações não agrícolas, aumento do número de pessoas aposentadas pelo sistema especial de previdência rural e pelo crescimento do número de beneficiários dos programas de transferências. Desse modo, ao analisar as causas da pobreza, foi possível verificar se essas mudanças contribuíram para a mitigação da pobreza no campo. 
Os resultados indicaram que, quanto mais próximo do urbano, menos chances a família possui de experimentar a pobreza. Mais uma vez, evidencia-se a vulnerabilidade do rural em termos de infraestrutura, pois esses lugares, mais distantes do urbano, são marcados pela falta de transportes, estradas não pavimentadas, falta de acesso à energia elétrica etc.

Quanto à expansão do regime especial de previdência rural, constata-se que ele ainda não foi suficiente para reverter o fator de vulnerabilidade para as famílias rurais. A presença de idoso na família ainda contribui para aumentar as chances de a família ser pobre. Em face de um período de aumento da previdência social no meio rural, era esperado pelo menos queda mais expressiva nessa probabilidade. Sugere-se estudos mais específicos, para analisar esse impacto.

No que diz respeito ao aumento das transferências de renda, observou-se que, ao elevar a renda dos pobres, as transferências têm impacto significativo na redução da incidência da pobreza. Transferências perfeitamente focalizadas, direcionadas para famílias com fator de vulnerabilidade, como a presença de criança, são interessantes para a diminuição da pobreza. Diante dos resultados, pode-se inferir que essas transferências estão sendo bem focalizadas no meio rural, uma vez que em 2011 e 2012 ter uma criança com idade inferior a 10 anos não aumenta as chances de entrar na pobreza. Se houve planejamento familiar ou aumento do acesso aos programas sociais como Bolsa Família ou Brasil Carinhoso, este estudo não pôde confirmar. Porém, como planejamento familiar é pertinente a sociedades desenvolvidas, pode-se inferir que as transferências estejam contribuindo para que, em uma fase importante da vida, menos crianças entrem na pobreza e, assim, o Brasil tem conseguido cumprir as metas do milênio.

Os resultados confirmaram que a discriminação por gênero é muito forte no meio rural. Como salientado, é preciso mais que desenvolvimento econômico para mudar esse quadro, passando por uma reforma cultural com o auxílio de leis trabalhistas mais preparadas para fiscalizar e coibir esse tipo de discriminação.

Embora o cenário da pobreza seja de queda, ainda se verificaram 10.916.612 pessoas na pobreza no meio rural do Brasil, em 2012. Esse é um número alto que precisa ser reduzido, principalmente, no Nordeste e Norte, onde se observaram proporção relevante de pessoas na pobreza e fraca tendência de queda.

Uma das limitações da pesquisa é que as análises realizadas sobre os rendimentos captam apenas o valor da renda monetária. Fica-se de fora uma importante parcela da renda no meio rural, relacionada às atividades de produção para o autoconsumo, que pode contribuir para superestimar a quantidade de pessoas pobres. 


\section{Referências bibliográficas}

ALBUQUERQUE, R.C.D. Estratégia de desenvolvimento e combate à pobreza. 1995. SCIELO. Disponível em: <http://www.scielo.br/scielo.php?script=sci_arttext\&pid=S0103$40141995000200004 \& \operatorname{lng}=\mathrm{en} \& n r m=i s o>$. Acesso em: Mar. 2014.

AMUEDO-DORANTES, C. "Determinants and Poverty Implications of Informal Sector Work in Chile," Economic Development and Cultural Change, vol. 52(2), pages 347-68, Jan. 2004.

ANDERSSON M.; ENGVALL A.; KOKKO A. Determinants of Poverty in Lao PDR (Working Paper \# 223.). Stockholm: Stockholm School of Asian Studies, 2006.

BANCO MUNDIAL. World Development Indicators Database. Disponível em: <https://data.worldbank.org/indicator/SI.POV.DDAY>. Acesso em: 19 nov. 218.

BANE, M. J.; ELLWOOD, D. Slipping Into and Out of Poverty: The Dynamics of Spells. Journal of Human Resources, 21 (1). 1986.

BARROS, R. P., et al. A Queda Recente da Desigualdade de Renda no Brasil. Rio de Janeiro: IPEA. 2007.

BOURDIEU, P. Podersimbólico. Lisboa: Bertrand, 1989.

BUAINAIN, A. M. A nova cara da pobreza rural: desafios para as políticas públicas. Brasília. IICA. 2012.

BUAINAIN, A.M.; DEDECCA, C. S.; NEDER, H. D. Projeto a nova cara da pobreza rural no brasil: transformações, perfil e desafios para as políticas públicas. IICA, 2010. Disponível em:<http://www.iica.int/Esp/regiones/sur/brasil/Lists/DocumentosTecnicosAbertos/Attachments/290/ Antonio\%20Márcio\%20Buainain\%20-.pdf>. Acesso em: maio de 2014.

CAMPELlO, T.; FALCÃO, T.; COSTA, P.V. Brasil Sem Miséria. Brasilia, MDS, 2014.

CELLINI, S. R.; MCKERNAN, S. M.; RATCLIFFE, C. The dynamics of poverty in the US: A review of data, methods, and findings. Journal of Policy Analysis and Management, 27 (3). 2008.

CHARLETTE-GUEARD; MESPLÉ-SOMPS. Comprehensive System of Social Security for South Africa, Viewpoint, South Africa Foundation. Johannesburg. 2001.

CHETTY R.; HENDREN N.; KLINE P.; SAEZ E. Where is the Land of Opportunity? The Geography of Intergenerational Mobility in the United States. NBER Working Papers 19843: National Bureau of Economic Research. 2014.

CORRÊA, A. M. C. J. Distribuição de renda e pobreza na agricultura brasileira (1981-1990) (1st ed.). Piracicaba: Editora UNIMEP. 1998.

DATT, G. et al. Determinants of Poverty in Mozambique: 1996-97, Draft Research Report. International Food Policy Research Institute, Washington, D.C. Photocopy. (http://www.csae.ox.ac.uk/conferences/2000-OiA/pdfpapers/simler.pdf - 10 junho 2004). 1999.

DEL GROSSI, M. Pobreza e extrema pobreza no Brasil rural. In: Buainain. (Org.). A nova cara da pobreza rural: desafios para as políticas públicas. Brasília: Instituto Interamericano de Cooperação para a Agricultura (IICA), 2012, v. 16, p. 319-334. 
DEL-GROSSI, M. E.; GRAZIANO-DA-SILVA, J. Mudanças recentes no mercado de trabalho rural. Parcerias Estratégicas, 22 (1). 2006.

DERCON, S.; KRISHNAN, P. Vulnerability, seasonality and poverty in Ethiopia. Journal of Development Studies, 36 (6). 2000.

FAO, IFAD and WFP. The State of Food Insecurity in the World 2014. Strengthening the enabling environment for food security and nutrition. Rome, FAO. 2014

FERREIRA, C. A.; SOUZA, S. As aposentadorias e pensões e a concentração dos rendimentos domiciliares per capita no Brasil e na sua área rural: 1991 a 2003. Revista de Economia e Sociologia Rural, 45 (4). 2007.

FISSUH, E.; HARRIS, M. Modelling determinants of poverty in Eritrea: A new approach. Monash University, Clayton, Victoria 3800, Australia: Department of Econometrics and Business Statistics. 2004.

FOFACK H. The dynamics of Poverty Determinants in Burkina Faso in the 1990s. unpublished document. 2002.

FOSTER, J.; GREER, J.; THORBECKE, E. Notes and Comments a Class of Decomposable Poverty Measures. Econometrica, 52 (3). 1984.

GEDA et al. "Determinants of Poverty In Kenya: A household Level Analysis", Discussion Paper, Institute of Social Studies, The Heag-the Netherlands. 2001.

GOAED, S.; GHAZOUANI, M. "The determinants of urban and rural poverty in Tunisia," discussion paper, Laboratoired' Econométrie Appliquée (LEA), Faculté des Sciences Economiqueset de Gestion de Tunis, Tunisia. 2001.

GRAZIANO DA SILVA, J.; DEL GROSSI, M. E. Rural Nonfarm Employment and Incomes in Brazil: Patterns and Evolution. World Development, 29 (3). 2001.

GRAZIANO DA SILVA, J.; DEL GROSSI, M. Evolução da renda nas famílias agrícolas e rurais: Brasil, 1992/97. In Anais do XXVII Encontro Nacional De Economia (1st ed.). Niteroi - RJ: ANPEC Associação Nacional de Centros de Pós-Graduação em Economia. 1999.

GROOTAERT, C. The Determinants of Poverty in Côte d'Ivoire in the 1980s. Journal of African Economies, 6 (2). 1997.

HELFAND, S. M.; PEREIRA, V. F. Determinantes da Pobreza Rural e Implicações para a Política Pública no Brasil. IICA, 2011. Disponível em:<http://www.iica.int/Esp/regiones/sur/brasil/Lists/DocumentosTecnicosAbertos/Attachments/394/ Texto\%20Steven\%20Helfand\%20-\%20Final\%20-PT\%20126\%20NEAD.pdf>. Acesso em: novembro de 2014.

HESPANHOL, A. N. Manutenção e reprodução da pobreza rural no Brasil e o desafio da sua superação por meio de políticas públicas. Campo-Território: Revista de Geografia Agrária. Edição especial do XXI ENGA-2012, p. 1-17, jun. 2014.

HOFFMANN, R.; SIMÃO, R. C. S. Determinantes do rendimento das pessoas ocupadas em Minas Gerais em 2000: o limiar no efeito da escolaridade e as diferenças entre mesorregiões. Nova Economia, 15 (2). 2005.

HOFFMANN, R. Transferência de renda e a redução da desigualdade no Brasil e cinco regiões, entre 1997 e 2004. Econômica, 8 (1). 2006. 
HULME, D.; SHEPHERD, A. Conceptualizing Chronic Poverty. World Development, 31 (3). 2003.

IBGE. Instituto Brasileiro de Geografia e Estatística. Sistema de Contas Nacionais - Brasil, nota metodológica $\quad \mathrm{n}^{\circ} \quad 17 . \quad$ Disponível em: <ftp://ftp.ibge.gov.br/Contas_Nacionais/Sistema_de_Contas_Nacionais/Notas_Metodologicas/17_con sumo_final.pdf $>$. Acesso em: Fevereiro de 2015.

IFAD. \#FAFO 2014 - Farmers' Forum at IFAD eyes rural development from the grassroots. IFAD Social Reporting Blog. Disponível em: <http://ifad-un.blogspot.com.br/2014/02/fafo-2014-farmersforum-at-ifad-eyes.html>. Acesso em: março de 2014.

KABUBUO-MARIARA. The Linkages Between Property Rights, Migration and Productivity: The Case of Kajiado District, Kenia. Enviroment and Development Economics (forthcoming). 2002.

LAYTE, R.; WHELAN, C. T. Moving In and Out of Poverty: The Impact of Welfare Regimes on Poverty Dynamics in the EU. European Societies, 5 (2). 2003.

LIMA, R. Mercado de trabalho: o capital humano e a teoria da segmentação. Pesquisa e Planejamento Econômico, Rio de Janeiro, v. 10. 1980.

MALUF, R. S.; MATTEI, L. Elementos para construção de uma agenda de políticas públicas para o enfrentamento da pobreza rural. In: MIRANDA, C. E TIBÚRCIO, B. (orgs). Pobreza rural: concepções, determinantes e proposições para a construção de uma agenda de políticas públicas. Brasília, IICA, 15:26. (Série Desenvolvimento Rural Sustentável: edição especial). 2011.

MARINHO, E.; ARAUJO, J. Pobreza e o sistema de seguridade social rural no Brasil. Revista Brasileira de Economia. Rio de Janeiro, v. 64 n. 2, p. 161-174, 2010.

MARINHO, E.; LINHARES, F.; CAMPELO, G. Os programas de transferência de renda do governo impactam a pobreza no Brasil? Revista Brasileira de Economia. Disponível em: <http://www.scielo.br/scielo.php?script=sci_arttext\&pid=S0034-

71402011000300003\&lng=en\&nrm=iso >. Acesso em: março de 2014. 2011.

MARINHO, E.; SOARES, F. Impacto do crescimento econômico e da concentração de renda sobre a redução da pobreza nos estados brasileiros. In: ENCONTRO NACIONAL DA ECONOMIA, XXXI, 2003. Porto Seguro. Anais, Porto Seguro: ANPEC. 2003.

NEDER, H. D.; BUAINAIN, A. M.; SILVA, G. J. C. Rural Poverty in Brazil: a multidimensional measurement approach. Anais do 33o Encontro Brasileiro de Econometria, Foz do Iguaçu. 2011.

NEY, M. G.; HOFFMANN, R. Desigualdade de renda na agricultura: o efeito da posse da terra. Economia, 4 (1). 2003.

NUNES, F. Dinâmica de pobreza e eficácia do sistema de solidariedade e segurança social: uma aplicação a Portugal. Lisboa: Universidade Técnica de Lisboa. Instituto Superior de Economia e Gestão.2004.

OKWI, P. O. Poverty in Uganda, Economic Policy Research Centre working papers, Makerere University, Uganda. 1999.

ONU, Organização das Nações Unidas HABITAT. Estado de las Ciudades da América Latina y el caribe 2012. Disponível em: < http://estaticog1.globo.com/2012/08/21/Estado-de-las-Ciudades-de-AmericaLatina-y-el-Caribe-2012.pdf>. Acesso em: 19 nov. 2018

PATRIARCHA T. F.; PASTOR, M. Gênero e o movimento dos trabalhadores rurais sem terra. Anais do II Simpósio Gênero e Políticas Públicas, ISSN 2177-8248 Universidade Estadual de Londrina,18 e 19 de agosto de 2011.

PAUGMAN, S. O enfraquecimento e a ruptura dos vínculos sociais: uma dimensão essencial do processo de desqualificação social. In: As artimanhas da exclusão: análise psicossocial ética da desigualdade social (1st ed.). Petrópolis: Vozes. 1999. 
RESENDE, A. C. C.; OLIVEIRA, A. M. H. C. Avaliando resultados de um programa de transferência de renda: O impacto do Bolsa-Escola sobre os gastos das famílias brasileiras. Estudos Econômicos, 38 (2). 2008.

ROCHA, S. Transferências de renda federais: focalização e impactos sobre pobreza e desigualdade. Revista de Economia Contemporânea, 9 (1). 2008.

ROCHA, S. Pobreza no Brasil: Afinal, de que se Trata? Rio de Janeiro: Editora FGV. 2006.

RODRIGUES, E. V., et al. A Pobreza e a Exclusão Social: Teorias, Conceitos e Políticas Sociais em Portugal. Ler Letras, 1999. Disponível em:<http://ler.letras.up.pt/uploads/ficheiros/1468.pdf>. Acesso em: maio de 2014.

SANTOS, G. C.; FONTES, R. M. O.; BASTOS, P. M. A.; LIMA, J. E. de. Mercado de trabalho e rendimento no meio rural brasileiro. Economia Aplicada. 2010.

SAWAYA, A. L.; SOLYMOS, G. M. B.; FLORENCIO, T. M. M. T.; MARTINS, P. A. Os dois Brasis: quem são, onde estão e como vivem os pobres brasileiros. Estud. Av. [online]. 2003.

SCHINEIDER, S. A pluriatividade na agricultura familiar. Porto Alegre: Editora da UFRGS. 2003.

SEN, A. Desigualdade reexaminada. Rio de Janeiro: Record, 2001.

. Desenvolvimento como liberdade. São Paulo: Companhia das Letras, 2000.

Development as freedom, Oxford, Oxford University Press. 1999.

. Inequality Re-examined. New York: Russell Sage Foundation. 1992.

. The Concept of Development. In: CHENERY, H. and SRINIVASEN, T. N. Eds. The Handbook of Development Economics Volume I. Amsterdam: Elsevier Publishers, 1988.

Equality of What? In: MCMURRIN, S. Ed. Tanner Lectures on Human Values. Cambridge: Cambridge University Press, 1980.

'Poverty: An Ordinal Approach to Measurement', Econometrica, 44(2): 219-231. 1976.

SHAMS K. Determinants of Subjective Well-Being and Poverty in Rural Pakistan: A Micro-Level Study. Social Indicators Research. 2014.

SILVA, A. M. R. Abordagens das necessidades humanas e das capacitações: uma aplicação da metodologia de Alkire e Foster para o estudo da pobreza multidimensional em Minas Gerais nos anos de 2000 e 2010. 2015. 318 f. Tese (Doutorado em Ciências Sociais Aplicadas) - Universidade Federal de Uberlândia, Uberlândia, 2015.

SINGH J. P. Development Remix: Representing Poverty, Culture, and Agency in the Developing World. Early View (Online Version of Record published before inclusion in an issue): International Studies Perspectives. 2013.

SOARES, S.; SOUZA L.; SILVA, W.; SILVEIRA, F. G.; CAMPOS, A. Perfil da pobreza: Norte e Nordeste rurais. 2016. Disponível em: http://www.ipcundp.org/pub/port/Perfil_da_pobreza_Norte_e_Nordeste_rurais.pdf. Acesso em JAN 2017.

TOWNSEND, P. Measuring Poverty. British Journal of Sociology, 5 (2). 1954.

TRONCO, G. B.; RAMOS, M. P. Linhas de pobreza no Plano Brasil Sem Miséria: análise crítica e proposta de alternativas para a medição da pobreza conforme metodologia de Sonia Rocha. Rev. Adm. Pública, Rio de Janeiro , v. 51, n. 2, p. 294-311, Mar. 2017. Disponível em: $<$ http://www.scielo.br/scielo.php?script=sci_arttext\&pid=S0034-

76122017000200294\&lng=en\&nrm=iso >. Acesso em: 19 Nov. 2018. http://dx.doi.org/10.1590/00347612162786.

VEIGA, J. E. A Encruzilhada Estratégica do Brasil Rural. NEAD. Brasília, 2001. 
WAQUIL, P. D. A Nova Cara da Pobreza Rural no Brasil: transformações, perfil e desafios para as políticas públicas. IICA. Disponível em: <http://www.iica.int/Esp/regiones/sur/brasil/Lists/DocumentosTecnicosAbertos/Attachments/318/ 0\%20Produto $\% 203 \% 20-\% 20$ Especificidades $\% 20 \mathrm{do} \% 20$ Sul $\% 20-\% 20$ Paulo $\% 20$ Waquil $\% 20$ \%20revisado\%20março\%202011.pdf >. Acesso em: março de 2014. 2011.

WATERHOUSE, R. Vulnerability in Mozambique: Patterns, trends and responses. In - (ed.), II Conferência do IESE "Dinâmicas da Pobreza e Padrões de Acumulação em Moçambique Maputo: (s.n.), 2009.

WEIR, S.; KNIGHT, J. "Adoption and diffusion of agricultural innovations in Ethiopia: the role of Education". University of Oxford: Centre for the Study of African Economies. 2000.

WOOD, G. Staying Secure, Staying Poor: The "Faustian Bargain”. World Development, 31 (3). 2003.

ZHANG, Y.; WAN, G. How Precisely Can We Estimate Vulnerability to Poverty? Oxford Development Studies, v. 37, n.3, Sep 2009. 